\title{
The Most Invisible Maternal Experience? Analysing How Maternal Regret Is Discussed in Finland
}

\author{
Tiina Sihto and Armi Mustosmäki
}

\section{Abstract}

In Finland, becoming a mother is often constructed as an individual choice that ultimately leads to personal fulfilment and happiness, despite the occasional 'negative' feelings associated with motherhood such as exhaustion, frustration and tiredness. In this cultural atmosphere, maternal regret continues to be a subject that is hidden, forbidden and rarely scrutinised. It is perhaps surprising that in one of the world's most gender egalitarian countries, which is also perceived to be one of the best countries in which to be a mother, women still testify that motherhood is limited to survival. We argue that, somewhat paradoxically, discussing the negative emotions of motherhood might be particularly difficult in a relatively gender egalitarian society, where family policies are (by international comparison) fairly comprehensive and where becoming a mother is strongly constructed as a 'free choice'. These discourses often hide the fact that parenthood in Finland is still extremely gendered. Finland's masculine work culture with long working hours, the tendency for mothers and fathers not to take equal parental leave periods, and the cuts to welfare state

T. Sihto $(\bowtie) \cdot$ A. Mustosmäki

University of Jyväskylä, Jyväskylä, Finland

e-mail: tiina.sihto@jyu.fi services for families all contribute to the gendered division of parenthood. What are rarely discussed in connection with the struggles of mothering are political demands to improve gender equality. This chapter analyses discussion of maternal regret on an anonymous Finnish online discussion board. In comments from regretful mothers, motherhood is constructed as all-consuming, draining work. Hiding regret, especially from children, is seen as essential, as these mothers fear that their lack of 'correct' feelings will have adverse effects on their children. In comments responding to these regretful mothers, disbelief is a recurring theme with commenters suggesting that regretful mothers have misrecognised self-inflicted exhaustion or postnatal depression as regret. Such individualising responses depoliticise regret, contributing to the maintenance of taboos around motherhood.

\subsection{Introduction: Contemporary Cultural Ideals of Motherhood in Finland}

In 2020, the World Economic Forum's Global gender gap report rated Finland the third most gender egalitarian country in the world behind two other Nordic countries, Iceland and Norway (World Economic Forum 2020). Throughout the 2010s, Finland was also rated as one of the best 
countries in which to be a mother, again alongside other Nordic countries. By international comparison, Finland is a relatively wealthy society with low infant and maternal mortality rates as well as relatively low levels of maternal and childhood poverty (e.g. Save the Children 2015). ${ }^{1}$ Nordic welfare states aim for gender equality and strong welfare support for working parents, attracting international interest in and praise for these countries as 'Nordic nirvanas' (Lister 2009), particularly with regard to women and (working) mothers. The Finnish welfare state provides free maternity and child healthcare, and parental leave entitlements with job protection. ${ }^{2}$ In addition, children have a universal right to early childhood education, which is relatively affordable and of good quality. In part because of these relatively well-developed societal institutions and gender egalitarian policies, it is often thought that in Finland nobody 'has to become' a mother e.g. due to economic, societal or cultural reasons, and that motherhood is a 'free choice' for those who do eventually become mothers (e.g. Berg 2008; Sevón 2005).

However, the everyday realities of parenthood in Finland are not so straightforward: the division of parenthood is still extremely gendered and the role of mothers as the main providers of care is much more prominent than in other Nordic countries. One example of this is the division of parental leave. After the birth of a child, the Finnish parental leave scheme allows parents to care for their child(ren) full-time until the youngest child is three. The scheme mostly consists of gender-neutral leave entitlements, so parents can share their leave equally or indeed the father can even take a larger share of leave than the mother (see e.g. Salmi et al. 2019). However, mothers take over $90 \%$ of parental leave (Social Insurance Institution of Finland 2019). ${ }^{3}$ Differences also emerge regarding how

\footnotetext{
${ }^{1}$ The index used by Save the Children (2015) consists of indicators measuring mothers' and children's health as well as their educational, economic and political status.

${ }^{2}$ For a detailed description of the wide range of family policies available, see Salmi et al. (2019).

${ }^{3}$ One quarter $(25 \%)$ of fathers do not take parental leave (not even the leave entitlements specifically earmarked for
}

much time mothers and fathers invest in childcare and housework. Although new parents today in general spend more time with their children than did previous generations, mothers of young children still spend twice as much time on childcaring duties as fathers (Pääkkönen and Hanifi 2011). ${ }^{4}$

Cultural ideals regarding childrearing have changed in ways that particularly stress the role of the mother as practices of 'intensive mothering' (Hays 1996) have been on the rise during recent decades. These practices are characteristically time-consuming, child-centred, expertguided, emotionally absorbing, labour-intensive and financially expensive. In Finland, ideals that stem from attachment theory have reinforced the notion that women should be temporary homemakers during the first 3 years of a child's life. ${ }^{5}$ This is also reflected in childcare preferences. Children's participation rates in early childhood education are much lower in Finland compared with other Nordic countries (OECD 2019).

Although Finnish mothers work full-time more often than their counterparts in other Nordic countries, Finns have relatively traditional attitudes and practices concerning the division of paid work and childcare. Compared with other Nordic populations, Finns are more likely to support the idea that men should be in charge of earning a livelihood for the family while women should take more responsibility for childcare (Salin et al. 2018). As a result, despite the strong welfare state, in many ways, Finland constitutes

them) and half of fathers only take the parental leave days that are available simultaneously with the mother's leave (Eerola et al. 2019).

${ }^{4}$ Mothers in families where the youngest child is under school age (i.e. under the age of seven) spend two hours and 44 min per day on childcare (excluding housework), whereas fathers spend one hour and 21 min (Pääkkönen and Hanifi 2011).

${ }^{5}$ Attachment theory was popularised by psychiatrist John Bowlby in the 1950s. The theory suggests that a child needs the constant presence of a loving and responsive attachment figure - typically the mother. The presence or absence of this figure is seen as having lifelong consequences for the mental health of the child. For a deeper discussion and critique, see Lee et al. (2014). 
a rather 'traditional' gender culture (PfauEffinger 1998).

Consequently, the experience of contemporary motherhood in Finland is much more multifaceted and is embedded with much more gender inequality than might seem to be the case at first glance. Moreover, reducing the question of whether or not to become a mother to a matter of 'free choice' underestimates the role played by historical, cultural and social factors in women's decisions about having children (see also Berg 2008; Donath 2015a). Therefore, the complexities of the maternal experience in Finland need further unpacking.

In this chapter, we are interested in the experiences and emotions of Finnish women who regret motherhood. We analyse data gathered from an anonymous Finnish online discussion board. We are particularly interested in (i) descriptions of regret, (ii) how and why regret is kept hidden and (iii) what kinds of reactions arise when this invisible regret is made visible. We argue that an analysis of regretting motherhood helps us to understand not only the phenomenon itself but also motherhood in the Finnish context more broadly and deeply. In doing this, we hope to illuminate the blind spots in current debates concerning gender equality and motherhood and to analyse the limits of 'acceptable' maternal emotions.

\subsection{Regretting Motherhood: A Hidden Experience}

The ambivalence of motherhood has been extensively mapped in previous research. ${ }^{6}$ The mothering experience is paradoxical, characterised by contradictory emotions arising from the rewards, responsibilities and satisfactions that childrearing brings and their coexistence with boredom, hard work and pain (e.g. Miller 2005; Sevón 2009). In contemporary public discussions

\footnotetext{
${ }^{6}$ For a more detailed discussion of structural ambivalence (i.e. incongruence between societal expectations and personal preferences) and psychological ambivalence (i.e. simultaneous emotions of love and hate), see Sevón (2009).
}

too, 'negative' emotions evoked by motherhood are discussed relatively often. It has become increasingly acceptable to confess that motherhood is not always wonderful and emotionally and/or mentally fulfilling, but can at times be repetitive, tiring and exhausting. The ways of speaking about motherhood have become more diverse, and it has become more acceptable to question and ironise the normative picture of 'good motherhood', for example through confessions about being a 'bad mother' (Jensen 2013: Lehto 2019). Yet these discourses are often followed by descriptions of how, despite all the struggles, the loved one feels towards one's child makes it all worthwhile. The socially shared norm regarding motherhood is that all mothers want to be mothers, and even those who struggle with the role will eventually grow into it and learn to enjoy motherhood.

Consequently, the possibility of regret remained largely invisible in public discussions as well as in research until the mid-2010s when pioneering research on regretting motherhood by Israeli sociologist Orna Donath (2015a, b, 2017) was published. As noted in the following chapter by Heffernan and Stone (see Chap. 11), Donath's research was groundbreaking not only academically but also for the public discussion of (regretting) motherhood as it shed light on a phenomenon that had previously remained largely hidden. In her research, Donath (2015a, b, 2017) interviewed 23 Israeli women who admitted to regretting motherhood. Donath distinguished regret from other conflictual emotions such as ambivalence. The women in her study self-identified as regretful mothers-mothers who, if given the choice again, would not choose to become mothers.

As a feeling, regret is characterised as a negative moral emotion with strong personal choice and responsibility attached to it (Aronson and Fleming 2018; Gilovich and Medvec 1994). For example, grief or rage can be felt after something happens over which one has no control (for example, falling seriously ill), but regret is felt where one feels one could have acted differently but did not. Thus, regret presumes strong individual agency: actual choices have been made, 
and various options were available, but the road one eventually took was not the right one. Regret about parenting is often related to looking back and feeling that one was too absent from the lives of one's offspring (Roese and Summerville 2005; see also Moore and Abetz 2019), and alsoparticularly for women-regret over the timing of having children and the opportunities one has missed outside one's family roles (Aronson and Fleming 2018; DeGenova 1996). Consequently, the regrets people tend to have often involve inaction rather than action and, particularly, in the long run, people regret the chances they have missed and the roads they have not taken (e.g. Gilovich and Medvec 1994). This is often thought to be the case with (not) having children as well. The hegemonic cultural norm is that while not having children can be a source of regret, having children cannot be something one regrets, and especially not if one is a woman. Hence motherhood is socioculturally constructed as a 'mythical nexus that lies outside and beyond the human terrain of regret' (Donath 2015b, p. 347).

Donath's (2015a, b, 2017) research not only relates the experiences of regretful mothers but also illuminates the broader societal picture of contemporary motherhood. The cultural 'feeling rules' (Hochschild 1979) ${ }^{7}$ surrounding motherhood do not allow us to question the emotional satisfaction gained from mothering, let alone to recognise that there may be deep-rooted feelings of regret in relation to the societal role of motherhood as such. Donath's interviewees emphasised the love they felt towards their child (ren) while simultaneously describing how they did not enjoy the role of being a mother or felt that motherhood was in conflict with their identity.

In this chapter, we relate our own research on regretting motherhood in Finland to the research that Donath conducted in Israel, a pro-natalist

\footnotetext{
${ }^{7}$ According to Hochschild (1979), feeling rules are socially shared norms regarding how it is acceptable or desirable to feel in a given social situation. The feeling rules of motherhood concern, for example, how one 'should' feel in a given situation in relation to the childe.g. after the birth, or when the child starts day care.
}

state where motherhood is still constructed as an essential role for women. In Finland, having a child is constructed above all as a question of 'free choice' (Berg 2008; Sevón 2005). However, if one does become a mother, the cultural norms and ideals of motherhood appear to be very restrictive (e.g. Mustosmäki and Sihto 2019). We argue that in Finland, the discourse surrounding 'free choice' and the culture of intensive motherhood (Hays 1996) make it particularly challenging to discuss maternal regret. This also makes understanding and contesting hegemonic cultural norms surrounding motherhood difficult.

\subsection{Data and Methods}

In this chapter, we analyse a thread on the anonymous Finnish online discussion board vauva.fi, which focuses mostly on topics related to motherhood, pregnancy and family life (vauva is the Finnish word for 'baby'). Vauva.fi is one of Finland's most popular websites and is similar to websites such as Mumsnet in the United Kingdom. The title of the discussion thread analysed in this chapter can be loosely translated as 'Those of you who regret having children: does the feeling ease off as the children grow up?' There were a total of 754 messages, of which 61 were explicit confessions of regret. ${ }^{8}$ The other messages were of varying kinds, mostly worrying or moralising about the topic of maternal regret and giving advice to those who express such regret. The discussion appeared online in early 2017 and all the comments in the thread were posted within a span of one week.

When we started our research, we decided to gather data from an anonymous discussion board for a variety of reasons. First, these boards offer rich sets of data where mothers confess their feelings. Previous research (Jensen 2013; Pedersen 2016; Pedersen and Lupton 2018) has identified the potential of anonymous discussion

\footnotetext{
${ }^{8}$ The 61 'explicit confessions of regret' were all messages where the commenters explicitly self-identify as regretful mothers (cf. Donath 2015a, b).
} 
boards for research on negative emotions about motherhood. On these discussion boards, the expression of emotions that are understood as negative, such as anxiety and anger, is seen as acceptable, but only to a certain extent. Additionally, in analyses of these discussion boards, the most forbidden maternal emotion-regrethas remained largely hidden (however, see Moore and Abetz 2019; Mustosmäki and Sihto 2019). Second, in her research on regretting motherhood in the Israeli context, Donath (2015a, b, 2017) described the difficulties she faced in recruiting interviewees, as people were often unwilling to discuss such a taboo topic face-to-face. Consequently, we decided to study an anonymous discussion board in order to get a glimpse into this relatively hidden phenomenon in Finland.

As the discussion is anonymous, we have no way of knowing the background of the women in our data, such as their ages, places of residence, marital statuses or social classes. However, previous research (Jensen 2013; Pedersen and Lupton 2018; Pedersen 2016) has shown that often these commenters on anonymous discussion boards that focus on family life are relatively privileged, middle-class women. The majority of the commenters do not explicitly specify their family situations (numbers or ages of children), nor when or how they first realised that they had feelings of regret. However, it is possible to deduce from the comments that these women are from relatively varied backgrounds and life stages: some state that they have young children, while a few are mothers of adult children; some mention their (male) spouses and children's fathers, while a few identify themselves as divorced or single mothers. A couple mentions having felt regret even before the birth of the child, while some write that their regrets emerged later. As in Donath's (2015a, b, 2017) work, there seems to be no uniform path or life situation that leads to regret.

Our analysis is based on data-driven thematisation. We separate utterances of regret from comments made by those who do not express regret themselves but participate in the discussion. We use the letter $\mathrm{C}$ to designate a comment, together with the number of the comment (e.g. 'C323'). In the following analysis, we first focus on descriptions of regret. Next, we explore mothers' motivations and strategies for keeping their regret hidden. In the last part of the analysis, we investigate the kinds of responses evoked in other discussants when this invisible regret is made visible.

\subsection{Describing Regret}

The regretful mothers in our data articulated a sense of being overwhelmed by how much their lives changed after they became mothers. They described being tired and exhausted as they felt that the role of being a mother is temporally, emotionally and mentally all-consuming. The following quote captures this sentiment.

Today I went skating with my children, built them
a skating rink, took time and encouraged them,
went to the library with the kids to borrow books
and then read them, danced with my daughter
while we were cleaning, built Lego with the kids,
played with my own and my neighbours' kids
outside, taking them to 'prison' to suffer their
'punishment', tickling, and we asked each other
riddles in the sauna, like we always do. I'm just an
ordinary mother.

Yet deep down I have this feeling that I cannot bear family life. If I could make the choice now, I wouldn't have children. I can't bear the worrying, housework, constant fulfilling of needs, fighting, noise, lack of sleep, I basically cannot bear anything that is included in family life. Today was ok, but if I could freely choose, I would've done something completely different today from what I did. (C41)

The regretful mothers in our data seemed to be very attached to cultural ideals of good motherhood. They gave long lists of the activities in which they must engage in order to meet the standard of being 'just an ordinary mother'. These women's accounts of their everyday lives resonate strongly with ideals of intensive mothering (e.g. Hays 1996; Smyth and Craig 2017), where mothers are required to devote significant amounts of time and to be constantly emotionally present for their children. In addition, mothers described the amount of 'cognitive labour' 
(Daminger 2019) that comes with raising children': 'one has to remember medical appointments, hobbies, to keep the fridge filled, to buy the appropriate clothes for the season in time, and the messaging with the school on top of that' (C106).

It is notable that these mothers described in great detail the responsibilities they shoulder, but the father's role is rarely mentioned. Amid their hectic lives with the child(ren), regretful mothers miss the lives they lived before they had children, or dream of a childless life. They long for time for themselves, their relationships and/or their careers. Life without children is portrayed as careless, hedonistic and free where one is able to do things spontaneously, such as: 'going to concerts, cafes, parks with friends (who are over 30 and childless, that's how it is nowadays...), nap in the middle of the day, go away somewhere spontaneously. Focus on your career and relationship' (C106).

These narratives of freedom might reflect the centrality of the idea of free choice around reproductive decisions in Finland. It is possible to question the choice to have children when there appear to be more life trajectories available than the heteronormative linear life course. If women's imaginations are colonised, as Donath (2017) suggests, they cannot imagine that any future other than motherhood is possible for themselves. Similarly, some mothers in this research confessed that they had their children because they thought that a heteronormative nuclear-family life would make them happiest. However, since having children, they realised that being a mother does not fit with their identity. For some, the longing for more time, space and tranquillity is a question of who they are, which is in contradiction with being a mother. For example, 'after having my child, I realised

\footnotetext{
${ }^{9}$ Cognitive labour involves the 'orchestration of everyday life', such as managing time, anticipating needs, acquiring information, comparing options, making decisions, and taking care of social relations, such as by remembering and organising birthdays and buying gifts. These are responsibilities that particularly fall to women, making them the 'project managers' in the family (Daminger 2019).
}

that I am a person who needs a lot of time for myself, silence, space for my own thoughts, and rest' (C87).

In addition to the physical and cognitive labour that comes with childrearing, the emotional aspects of mothering also take their toll on mothers. Feelings of guilt tied to regret are a frequent theme in the data. Despite their own efforts, the regretful mothers lived with the anxiety that they had failed or somehow will fail at mothering. According to a study by Liss et al. (2013), guilt is related to fear of being evaluated as a bad parent, or of being unable to meet the norms of good parenting. In the online discussion, regret was tied to the heavy responsibility and constant guilt that accompany raising a child:

I would have got along without this constant guilt, bad conscience and worry over the child and his happiness. Now, as the child has grown up and I am no longer responsible for another person's life, I have less of these feelings, but still I feel that this phase of life with children at home took more than it gave. $(\mathrm{C} 114)$

Statements such as these, which articulate responsibilities, difficulties and consequent guilt, may be understood as signs that women recognise the norms of good motherhood and the elusiveness of those norms. Guilt is often understood as an essential part of mothering as it guides women towards 'right' ways to mother (Elvin-Nowak 1999). Guilt also weighed on the Israeli mothers in Donath's (2015a, b, 2017) research. As in Donath's research, many regretful mothers in our study were overwhelmed by the tasks, responsibilities and emotional burden that comes with mothering. For them, motherhood is an exhausting, all-consuming role that binds them, wears them down and pushes them to their limits. As one commenter explained 'the constant demand to be the support person/cook/ entertainer/service troops etc. is lethal [...]. My life has been all about survival for years' (C236).

It is possible to conclude - as Donath (2015b) does - that the experiences and feelings these mothers describe are not unique, but the conclusions they draw from them are. While many mothers find the demands of motherhood a strain, they evaluate the struggle as worthwhile 
or as incomparable to the joys and happiness that come along with motherhood, and they would still choose motherhood again. However, with statements such as 'I wish I had known that I would feel that I have wasted my life' (C110), regretful mothers draw the conclusion that motherhood has ultimately taken more than it has given.

\subsection{Hiding Regret}

One of the most pressing reasons for keeping such regret hidden is the fear of causing harm to the child. The regretful mothers express the fear that their child(ren) will 'sense' that they regret motherhood or do not enjoy it in the ways they are expected to, and that this will damage the child, even in cases where the mothers never voice their feelings of regret to anyone, let alone to their children. Consequently, the regretful mothers describe it as their maternal duty to protect their child(ren) from their feelings of regret and see these feelings as potentially dangerous to the child(ren). As noted in the first part of our analysis, many regretful mothers also seemed to be committed to the ideals of intensive motherhood and did not criticise those ideals openly. A few regretful mothers did reflect on whether it is necessary to strive towards these ideals, but even in these descriptions, their understanding of 'good enough' motherhood often seemed to be synonymous with intensive motherhood as expressed by the following respondent:

Even though I regret my children, I want to be a good mother to them, and I feel that I have to do things which I otherwise wouldn't do in my free time. For example, cooking, ice skating, cycling, driving the kids to their hobbies, watching their hobby performances, reading the same book for the 100th time etc.

Even though I made a wrong choice when I had my children, there's no use crying over spilt milk, but now I have to try to be a good enough mother. And I still emphasise that I'm not overdoing [motherhood] or always in a good mood, or I don't do things that much with the children. But you just have to do things to some extent, because I don't want my children to suffer from my choices. (C242)

Earlier research has recognised that mothers adhere to the ideals of intensive motherhood and find it difficult to resist those ideals, even when following them entails unfavourable outcomes for the mothers themselves, such as limiting their autonomy (e.g. Smyth and Craig 2017). Even in cases where our commenters were negotiating the boundaries of what constitutes 'good enough' mothering, ensuring a 'normal childhood' for their child(ren) signified that mothers will engage in various time-consuming activities and hide their own feelings. Mothers seemed compelled to adhere to these norms because they do not want to risk their child(ren)'s future.

These comments on mothers' essential role in the future of their child(ren) reflect deterministic mothering. This notion is the idea that even the small, mundane choices one makes as a parent will have a direct influence on the child's later social, educational and economic success (e.g. Furedi 2001). Consequently, it is feared that easing off on these standards will risk the child's future. Deterministic mothering was reflected in the ways in which regretting mothers worry about how their negative feelings, or lack of 'correct' feelings, pose risks to the child and his/her future. In the commenters' descriptions, this view of their own behaviour as a threat can sometimes make motherhood even more exhausting and thus an even bigger source of regret, a vicious circle that one commenter describes as a 'vortex'.

It's a vortex: when it gets tough and you feel things are going the wrong way, you start to get anxiety about causing trauma for the children, trauma that you will have to mourn for the rest of their lives (and your own), and this causes more shitty feelings, so you cannot cope etc. (C37)

Consequently, not only is it the mother's task to protect the child(ren) from risks from the outside world, but mothers themselves constitute a risk factor in their children's lives. These deterministic ideas appeared to intensify the anxiety and guilt felt by mothers, forcing them to put their own needs aside so that their children 
will not suffer. Mothers hide their authentic feelings, hopes and desires, and do their best to manage the (emotion) work of mothering. ${ }^{10}$ However, the deterministic view lays particular responsibility on mothers, making the role of the mother intolerably burdensome (see also Furedi 2001). As one commenter puts it: 'I'm suffering so that the children can live quite normal lives' (C125). Thus, protecting the child from the mother's inappropriate emotions is an unquestionable moral obligation that relegates the mother's needs to secondary importance (e.g. Read et al. 2012), even if this entails feelings of suffering for the mother herself.

\subsection{Facing Regret}

As maternal regret has been mostly absent from public discussions in Finland, for many people the experience is unknown and difficult to comprehend. This is visible in our data as the majority of the comments were not about experiences of maternal regret, but rather were comments where others try to make sense of the experiences and feelings that the regretful mothers express.

One kind of response was for other commenters to deny the existence of regret. Many shared the view that mothering was a challenging task that can lead to exhaustion. Some commenters were mothers themselves and related to the feelings expressed by the regretful mothers. However, the regretful mothers were seen as misrecognising their own feelings or misinterpreting other mental states as regret. Instead of 'truly' regretting, the regretful mothers were understood to be tired or suffering from (postnatal) depression:

I have a child with special needs, who is really challenging. Right now, I'm really irritated with him/her, but I recognise that I'm just tired. Are you sure that this is not a case of being tired? If you are worried about your child, already that means that $\mathrm{s} / \mathrm{he}$ is very special and dear to you. (C52)

\footnotetext{
${ }^{10}$ Emotion work refers to 'inducing or inhibiting feelings so as to render them "appropriate" to a situation' (Hochschild 1979, p. 551).
}

Instead of having feelings of regret, the regretful mothers allegedly did not 'truly' understand their own feelings and mental states or the depth of love they feel towards their children. Some commenters suggested that the regretful mothers might develop a deeper understanding regarding how they 'truly' feel, which will lead them to realise that they do not 'truly' regret motherhood.

However, there were also comments that do not straightforwardly deny the existence of regret but nevertheless located the problem in the emotional and psychological realm. In several comments, sharing and working through one's emotions was seen to be important for the individual. These comments advised regretting mothers to take control of their emotional lives and manage their feelings of regret. Not sharing one's emotions was equated with being stuck in the feeling of regret, whereas confessing and dealing with one's emotions was seen as part of a growth process. The quote shared below explores this sentiment.

\footnotetext{
...if a parent is truly stuck in regret and neglects the child, that is a completely different thing than regretting in your own mind and confessing it here. [...] For some, processing their emotions and airing them can be just part of a growth process - a liminal stage before moving forward? (C312)
}

There seemed to be a firm belief that seeking medical and/or psychological support will help the regretful mothers. Some wrote of their own experiences, arguing that the regretful mothers will look back on all this later and understand that it was just a difficult temporary phase as the following commenter suggests.

I fell into postnatal depression, and when my illness was at its worst, I cried and regretted that I had ever decided to have a child, I was so tired and low. Now that I have received the necessary treatment and help, and some six months have passed, I am doing great with my child and my husband. (C730)

Some commenters emphasised that mothers should accept their role as mothers and learn how to take better care of themselves in order to be able to take better care of their families. Along these lines, mothers who confessed feelings of regret were not seen as bad or immoral. Instead, they were 'diagnosed' as depressed and portrayed as 
temporarily tired good mothers who had lost their way rather than as being 'truly' regretful (see also Dubriwny 2010). These views conflating regret with postnatal depression align with Donath's (2017) research. The ways in which such commenters direct attention away from regret and towards tiredness or depression reinforced the impression that it is socially very difficult to accept that a mother does not want to mother (also see Chap. 11 by Heffernan and Stone).

In addition to comments that addressed emotional and psychological issues, there were also comments that point towards the cultural ideals that weigh on mothers. Yet instead of challenging those ideals, these comments blamed regretful mothers for taking them too seriously. In this view, mothers exhausted themselves by trying to meet impossible standards, and their exhaustion and regret could have been easily dealt with by simply doing less: 'There are a lot of assumptions about what one MUST do with children, but is that really so?' (C488).

These comments advised mothers on how to live their everyday lives in a way that will enable them to carve out more space for themselves. They emphasised that children will not be damaged if a mother strives to be 'less perfect'. However, it was always seen as the individual's own responsibility to deal with hegemonic cultural ideals, to cope with the challenges of mothering and to strike a balance between perfect and bad mothering.

Some commenters, as well as regretting mothers themselves, also feared that mothers will be unable to hide their regret. Consequently, their children will sense their regret and it will cause them harm. However, the fear here was not only about ruining an individual child's life. Rather whole generations of mothers and children would supposedly be in danger if regret were to be discussed openly, which is represented in the quote below.

\footnotetext{
I absolutely agree that taboos should be discussed and the myth of perfect motherhood should be broken down and that the negative emotions of parenthood should be discussed. But this kind of whining won't do anything, we are just creating another extreme where mothers with good conscience can ruin their children's lives. (C320)
}

The idea presented here relies on a wider imaginary of moral corruption and contamination: dangerous ideas are contagious, like physical diseases, and they become equated with the prospect of moral corruption (see e.g. Wood 2018). These comments highlight that airing regret will give others permission to feel regret, making it normal and acceptable. If the boundary of acceptable maternal emotions were to be crossed and regret to be made visible, some commenters expected that this would lead to a proliferation of 'bad mothers'. Some comments directly interpreted maternal regret as a sign of larger-scale societal destruction. This catastrophising is encapsulated in comments such as 'Finland is on a road to ruin. Children are the future, and the future payers of your pensions' (C569). This echoes the idea that mothers and nuclear families are the moral backbone of society as well as fear over the future funding of the Finnish welfare state.

\subsection{Conclusions}

In this chapter, we have analysed regretting motherhood in the context of Finland. We have focused on descriptions of regret, how and why regret is kept hidden, and what kinds of reactions arise when such regret is made visible. We have also related our findings to seminal research by Donath $(2015 a, b, 2017)$ on maternal regret in Israel. Although Finland and Israel constitute two very different country cases, ${ }^{11}$ the experiences of maternal regret in our study seem strikingly similar to those in Donath's (2015a, b, 2017). These similarities between the experiences of Finnish and Israeli mothers point towards similarities in the maternal experience in general. No matter what the societal or cultural context, becoming a mother can lead to exhaustion, a loss of personal autonomy, and for some even a loss of identity. That is not to say that motherhood is

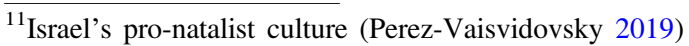
is reflected in its total fertility rate, which in 2017 was 3.1 compared with Finland's 1.35 (World Bank 2020). The fertility rate (the number of children women are expected to have during their life course) rapidly declined in Finland throughout the 2010s (Statistics Finland 2020).
} 
unbearable for the women in our data because of intensive or attachment parenting norms alonemothering can be exhausting even without any external expectations - but the ideals of good mothering do seem to intensify mothers' feelings of inadequacy and guilt. Regretful mothers engage in emotional work in order to hide their negative feelings, which in some cases further intensifies their feelings of regret.

The emotions expressed by the regretful mothers in our data are similar to the 'negative' and ambivalent feelings of mothers that have been identified in previous research (e.g. Liss et al. 2013; Miller 2005; Sevón 2009). Motherhood is not only a source of love, joy and meaning in life but also entails feelings of inadequacy, guilt, frustration, entrapment and anger, among others. It is possible to conclude, as Donath (2015b) does, that the experiences and feelings these mothers describe are not unique, but the conclusions they draw from those experiences are. As in Donath's research, the regretful mothers in our data draw the conclusion that motherhood has taken more than it has given. These women argue against the dominant narrative of motherhood, which claims that despite the trouble, motherhood is always worth it.

Donath (2015b) briefly discusses how maternal regret has remained hidden, pointing out that regret is pathologised or seen as an individual's personal failure to grow into motherhood. These lines of reasoning are also present in our data, particularly in the advice given to regretful mothers about 'what is to be done' in order to deal with regret. According to these responses, one should learn to resist toxic ideals related to mothering, learn how to parent, seek (medical/psychological) help and/or try to enjoy short blasts of hedonism, such as taking time for oneself and doing it 'with a good conscience'. Although a public discussion of negative feelings is considered to be necessary in order to abolish the 'myth of the perfect mother', the open public discussion of regret is still seen as societally dangerous. These responses are apolitical, in the sense that although they point towards mothers' overwork and gender inequality as sources of problems and they reject the mythology of the perfect mother, it is mainly seen as mothers' responsibility to cope with both the mundane and the mental challenges of parenting.

One might ask why maternal regret has emerged in public discussions now. One point of view is that it is perhaps only now that there are genuine possibilities for women to imagine choices and lives outside motherhood. Many of the regretful mothers in our data consider that they could have had meaningful, happy lives as childless women. This option seems to be available and appealing, if only they could go back in time knowing what they know now. Even though we have no way of knowing the background of women in our data, it is likely that the data does not represent 'all' women or mothers, but that the voices heard in the data are mainly those of white, relatively privileged middle-class women (see also Jensen 2013; Pedersen and Lupton 2018; Pedersen 2016). The comments are filled with descriptions of possible or imaginary futures without children as full of options, activities and freedom, and as unrestricted by a lack of resources. In this discussion thread, poverty and difficulties in providing for the family's basic needs do not emerge as a source of regret.

It is perhaps surprising that in one of the world's most gender egalitarian countries, which is also perceived to be one of the best countries in which to be a mother, women still testify that motherhood is limited to survival. We argue that, somewhat paradoxically, discussing the negative emotions of motherhood might be particularly difficult in a relatively gender egalitarian society, where family policies are (by international comparison) fairly comprehensive and where becoming a mother is strongly constructed as a 'free choice'. These discourses often hide the fact that parenthood in Finland is still extremely gendered. Finland's masculine work culture with long working hours, the tendency for mothers and fathers not to take equal parental leave periods, and the cuts to welfare state services for families all contribute to the gendered division of parenthood. What are rarely discussed in connection with the struggles of mothering are political demands to improve gender equality.

During recent years, declining fertility has become a major topic of public discussion as birth 
rates have reached an all-time low in Finland (Statistics Finland 2020). The debate around possible explanations and solutions for this has been heated and has been coloured by worries about how to finance welfare state services for the ageing population in the future. One of the suggested causes of the low fertility rate is the damaged 'brand' of family life. The claim is that there has been too much talk about the negative aspects, which has given childless people of childbearing age an unrealistically pessimistic view of family life and has led them not to have children at all. To present the 'rebranding' of family life as a solution to the low fertility rate depoliticises wider problems associated with the institution of motherhood, glossing over its associated gender inequalities. In this sociopolitical atmosphere, the public discussion of mothers' struggles becomes even more difficult, which acts to reconsolidate the taboo around maternal regret in Finland.

As will be discussed in more detail in the next chapter (Chap. 11) by Heffernan and Stone, Donath's research has received wide international attention in both old and new media. Newspapers have reported on the phenomenon and private individuals have participated in discussions on social media using the hashtag \#regrettingmotherhood. Given this context, it is notable that in Finland there has been very little public response to Donath's work or to the wider international discussion of regretting motherhood. There have been only a few short articles in the tabloids, translated from international news media. When Finland's biggest national newspaper printed a story based on the country's first published academic research article on maternal regret (Mustosmäki and Sihto 2019), there was a brief peak of interest in the national media, but the public discussion did not 'explode', as it did in the country cases analysed by Heffernan and Stone in the following chapter.

\section{References}

Aronson P, Fleming M (2018) Tapping and assessing the concept of educational regret: Methodological techniques for opening up biographical reflection. Contemp Social Sci 14(3-4):1-13
Berg K (2008) Äitiys kulttuurisina odotuksina (Väestöntutkimuslaitoksen julkaisusarja D 48). Väestöliitto, Helsinki

Daminger A (2019) The cognitive dimension of household labor. Am Sociol Rev 84(4):609-633. https://doi. org/10.1177/0003122419859007

DeGenova MK (1996) Regrets in later life. J Women Aging 8(2):75-85

Donath O (2015a) Choosing motherhood? Agency and regret within reproduction and mothering retrospective accounts. Women's Stud Int Forum 53:200-209. https://doi.org/10.1016/j.wsif.2014.10.023

Donath O (2015b) Regretting motherhood: a sociopolitical analysis. Signs: J Women Culture Soc 40(2): 343367. https://doi.org/10.1086/678145

Donath O (2017) Regretting motherhood: a study. North Atlantic Books, Berkeley, CA

Dubriwny T (2010) Television news coverage of postpartum disorders and the politics of medicalization. Feminist Media Stud 10(3):285-303. https://doi.org/ 10.1080/14680777.2010.493647

Eerola P, Lammi-Taskula J, O'Brien M, Hietamäki J, Räikkönen E (2019) Fathers' leave take-up in Finland: Motivations and barriers in a complex Nordic leave scheme. Sage Open 9:4. https://doi.org/10.1177/ 2158244019885389

Elvin-Nowak Y (1999) The meaning of guilt: a phenomenological description of employed mothers' experiences of guilt. Scand J Psychol 40(1):73-83. https://doi.org/10.1111/1467-9450.00100

Furedi F (2001) Paranoid parenting: Abandon your anxieties and be a good parent. Penguin, London

Gilovich T, Medvec VH (1994) The temporal pattern to the experience of regret. J Pers Soc Psychol 67(3):357

Hays S (1996) The cultural contradictions of motherhood. Yale University Press, New Haven, CT

Hochschild AR (1979) Emotion work, feeling rules, and social structure. Am J Sociol 85(3):551-575. https:// doi.org/10.1086/227049

Jensen T (2013) 'Mumsnetiquette': online affect within parenting culture. In Maxwell C, Aggleton P (Eds) Privilege, agency and affect (pp 127-145). Palgrave Macmillan, Basingstoke. https://doi.org/10.1057/ 9781137292636_8

Lee E, Bristow J, Faircloth C, Macvarish J (2014) Parenting culture studies. Palgrave Macmillan, Basingstoke. https://doi.org/10.1057/9781137304612

Lehto M (2019) Bad is the new good: negotiating bad motherhood in Finnish mommy blogs. Feminist Media Stud, 1-15. https://doi.org/10.1080/14680777.2019. 1642224

Liss M, Schiffrin HH, Rizzo KM (2013) Maternal guilt and shame: The role of self-discrepancy and fear of negative evaluation. J Child Fam Stud 22(8):11121119. https://doi.org/10.1007/s10826-012-9673-2

Lister R (2009) A Nordic nirvana? Gender, citizenship, and social justice in the Nordic welfare states. Social Polit: Int Stud Gender, State Soc 16(2):242-278

Miller T (2005) Making sense of motherhood: a narrative approach. Cambridge University Press, Cambridge 
Moore J, Abetz JS (2019) What do parents regret about having children? Communicating regrets online. J Fam Issues 40(3):390-412. https://doi.org/10.1177/ $0192513 \times 18811388$

Mustosmäki A, Sihto T (2019) Äitiyden katuminen intensiivisen äitiyden kulttuurissa. Sosiologia 56 (2):157-173

OECD (2019) OECD family database [Data set]. http:// www.oecd.org/els/family/database.htm

Pääkkönen H, Hanifi R (2011) Ajankäytön muutokset 2000-luvulla. Tilastokeskus, Helsinki

Pedersen S (2016) The good, the bad and the 'good enough' mother on the UK parenting forum Mumsnet. Women Stud Int Forum 59:32-38. https://doi.org/10. 1016/j.wsif.2016.09.004

Pedersen S, Lupton D (2018) 'What are you feeling right now?' Communities of maternal feeling on Mumsnet. Emotion, Space Soc 26:57-63. https://doi.org/10. 1016/j.emospa.2016.05.001

Perez-Vaisvidovsky N (2019) Israel: leave policy, familialism and the neoliberal welfare state. In Moss P, Duvander AZ, Koslowski A (Eds) Parental leave and beyond: Recent international developments, current issues and future directions, pp 75-90. Policy Press, Bristol. https:// doi.org/10.1332/policypress/9781447338772.003.0005

Pfau-Effinger B (1998). Gender cultures and the gender arrangement: A theoretical framework for cross-national gender research. Innov Eur J Soc Sci Res 11(2): 147166. https://doi.org/10.1080/13511610.1998.9968559

Read DMY, Crockett J, Mason R (2012) 'It was a horrible shock': the experience of motherhood and women's family size preferences. Women's Stud Int Forum 35 (1):12-21

Roese NJ, Summerville A (2005) What we regret most... and why. Personal Soc Psychol Bull 31(9): 1273-1285

Salin M, Ylikännö M, Hakovirta M (2018) How to divide paid work and unpaid care between parents? Comparison of attitudes in 22 Western countries. Soc Sci 7 (10):188. https://doi.org/10.3390/socsci7100188

Salmi M, Närvi J, Lammi-Taskula J, Miettinen A (2019) Finland country note. In Koslowski A, Blum S,

Open Access This chapter is licensed under the terms of the Creative Commons Attribution 4.0 International License (http://creativecommons.org/licenses/by/4.0/), which permits use, sharing, adaptation, distribution and reproduction in any medium or format, as long as you give appropriate credit to the original author(s) and the source, provide a link to the Creative Commons license and indicate if changes were made.

The images or other third party material in this chapter are included in the chapter's Creative Commons license,
Dobrotić I, Macht A, Moss P (Eds) International Review of Leave Policies and Research 2019, pp 1-22. International Network on Leave Policies \& Research. http://www.leavenetwork.org/lp_and_r_reports/

Save the Children (2015) State of the world's mothers 2015. https://www.savethechildren.org/content/dam/ usa/reports/advocacy/sowm/sowm-2015.pdf

Sevón E (2005) Timing motherhood: Experiencing and narrating the choice to become a mother. Feminism Psychol 15(4):461-482. https://doi.org/10.1177/0959353505057619

Sevón E (2009) Maternal responsibility and changing relationality at the beginning of motherhood (Jyväskylä Studies in Education, Psychology and Social Research 365). University of Jyväskylä

Smyth C, Craig L (2017) Conforming to intensive parenting ideals: Willingness, reluctance and social context. Fam Relat Soc 6(1):107-124. https://doi.org/ $10.1332 / 204674315 \times 14393034138937$

Social Insurance Institution of Finland (2019) Statistics on childcare benefits and their users. https://www.kela.fi/ documents/10180/1630873/Lapsiperhe_etuudet_ kuviot.pdf/1ce0ce45-d979-409d-a701-4e40bd2fa383

Statistics Finland (2020) Decrease in birth rate still continues. http://www.stat.fi/til/vamuu/2019/12/vamuu_2019_12_ 2020-01-23_tie_001_en.html

Wood H (2018) The Magaluf girl: A public sex scandal and the digital class relations of social contagion. Fem Media Stud 18(4):626-642. https://doi.org/10.1080/ 14680777.2018.1447352

World Bank (2020) Fertility rate, total (births per woman): Israel, Finland. https://data.worldbank.org/ indicator/SP.DYN.TFRT.IN?locations=IL-FI\&most_ recent_year_desc=false

World Economic Forum (2020) Mind the 100 year gap. https://www.weforum.org/reports/gender-gap-2020report-100-years-pay-equality/country-top-10s\#report-nav

unless indicated otherwise in a credit line to the material. If material is not included in the chapter's Creative Commons license and your intended use is not permitted by statutory regulation or exceeds the permitted use, you will need to obtain permission directly from the copyright holder. 